\title{
Digitization and Financial Reporting - How Technology Innovation May Drive the Shift toward Continuous Accounting
}

\author{
Sean Stein Smith ${ }^{1}$ \\ Department of Economics and Business, Lehman College, City University of New York, New York, NY, USA \\ Correspondence: Sean Stein Smith, Department of Economics and Business, Lehman College, City University of \\ New York, New York, NY, USA
}

Received: June 24, 2018

Accepted: June 10, 2018

Online Published: August 4, 2018

doi:10.5430/afr.v7n3p240

URL: https://doi.org/10.5430/afr.v7n3p240

\begin{abstract}
Technological forces, including but not limited to blockchain and artificial intelligence platforms, are driving change not only in the accounting profession, but business at large. In a business environment where data is produced nearly continuously, and stakeholder groups expect an increasing variety of information, current accounting processes do not appear sufficient. This research examines and applies current market forces, linked to both technology, including an analysis of both blockchain and artificial intelligence, and the increased influence of stakeholders on the reporting process, to do the following. First, an analysis of items to consider and review as the shift toward more continuous accounting and reporting begins is postulated. Second, and arguably more important for the combined practitioner and academic audience this research is intended for, implications and applications of more continuous accounting are put forth to assist as individuals and organizations embrace this transformative process.
\end{abstract}

Keywords: accounting, analytics, blockchain, artificial intelligence, disruption, continuous reporting

\section{Introduction}

The continued integration and implementation of technology tools, platforms, and processes throughout the business decision making process is already generating significant ramifications throughout the accounting profession. A review of practitioner and mass media publications yields examples that include both accounting specific organizations and applications underway in a number of industries. Although technologies such as artificial intelligence, blockchain, and the growing crypto-economy are still in the early stages of development and product roll out, the proverbial ripple effects are already being felt across geographic and industry lines. Organizations that include, but are not limited to the Big 4 public accounting firms are currently rolling out accounting tools and services based on the growing integration of tools like blockchain and AI in many arms of the business. Even with the growing investor interest and discussion about applications for technology tools, however, there does appear to be uncertainty with regards to just how the integration process will unfold. Specifically, and forming the basis for this analysis and research, there appears to be significant amounts of uncertainty related to just how these different technology tools will inevitably change the accounting profession. This uncertainty continues to exist even after acknowledging the reality that technology processes and systems, often categorized as accounting information systems (AIS) have long been an important part of the professional conversation.

While it does appear clear that nearly every facet and aspect of accounting and accounting information technology is in the process of evolving in the face of changing market conditions, the applications for practitioners remains fluid. Drilling down to the crux of the debate as well as the focus of this research, the technology tools themselves appear to be emerging as more mainstream topics, and the implications for accounting professionals appear worthy of increased analysis. Since the accounting and finance professions are already in the midst of several largescale changes, including demographics, the transition from billable hours to value based billing, technology integration at a broad based level, and remote based work, this additional change catalyst can have an outsized effect. In order to effectively recommend or suggest how different areas of the profession will change, however, it is first necessary to drill down into two of the most high profile technology applications in the marketplace. Namely, the continued investment in, and implementation of, blockchain technology options and artificial intelligence bots and tools should be evaluated as potential disruptors within the profession. 
Continuous accounting, as disruptive an idea as it may initially appear, is not evolving or developing in a vacuum by itself, or in and of itself. The trend and shift toward a more continuous and ongoing accounting is a reflection of not only changing dynamics and forces in the marketplace, but also accounting specific changes of interest to the profession. These trends include rather obvious topics such as blockchain, artificial intelligence, and the increasing importance of data as a business asset, but also trends that might not appear to be as initially connected. Stakeholder theory, bridging the gap between current reporting and the types of information, and synchronizing the speed of the market with the pace of reporting are both challenges and opportunities for accounting professionals. The impact these changes are already having can be seen at present throughout the marketplace, with this research adding to this dynamic conversation.

\section{Literature Review}

Although this research piece can, and should be, used by practitioner and academic users, a robust understanding of the specific areas driving change should be based in an analysis and examination of academic research on these topics. Even as the increased amount of technology becomes more mainstream and well observed within the profession, the emerging forces of blockchain and AI remain somewhat of an unknown both for practitioners and researchers. Perhaps the most logical step toward obtaining a more thorough understanding of how the profession will evolve over time is to first analyze, understand, and comprehend what said technologies and the differentiating characteristics versus current market options.

\subsection{Blockchain}

Blockchain technology, and especially the cryptocurrencies applications dependent on the blockchain technology and platform, became popular in the practitioner and media conversation toward the end of 2017 as prices of cryptocurrencies rose to unprecedented levels. Drilling down, however, the cryptocurrency application and marketplace is perhaps the first, but does not appear to be the last, iteration of innovation based on blockchain technology (Lewis, McPartland, \& Ranjan, 2017). Analysis and documentation of blockchain technology, including coverage in both practitioner and mainstream media, may have led some market participants to believe and project that the blockchain environment is experiencing a bubble-like environment. In order to understand the implications of blockchain technology, specifically as it pertains to the accounting profession, it appears appropriate to drill down into some of the characteristics that make blockchain technology different from existing marketplace options that have previously been adopted by firms and organizations (Carlozo, 2017). Blockchain characteristics, including those that are most important for accounting professionals and researchers include, but are not limited to, the following:

1) Immutability - once information has been approved and uploaded onto the blockchain platform it does not have the ability to be changed without leaving an easily seen, and auditable trail. Put another way, once the information contained within the blocks, which can be any type of information including financial and non-financial data, has been approved and verified by the consensus protocol embedded within the blockchain platform it is, for all intents and purposes, a permanent record.

2) Consensus based verification - while the specific of the verification method will vary from network to network, ranging from proof to work, to proof of stake, to other numerous iterations, the underlying rationale and implications are consistent. As information is uploaded onto the blockchain platform, and regardless of whichever specific software version is used, this consensus based verification and approval is core to the decentralized nature of the technology itself.

3) Decentralized - it is true that private blockchains will, in virtually every case, involve an organizing entity but the underlying purpose and nature of the blockchain platform is that it is a decentralized construct. Drilling down into the implications of this decentralized concept is the reality that, almost opposite to the current structure of centralized banking and finance verification and information, that blockchain technology will enable more widespread communication of information.

4) Encrypted - one of the most widely discussed attributes of blockchain technology, and the applications most widely discussed in the form of cryptocurrencies, is the reality that the information and data communicated and disseminated via blockchain technology is encrypted. The specifics of the encryption will again vary from network to network, but a common encryption technique is to rely on a combination of public key and private key verification. A simplistic explanation is that, in order to actually unlock and examine the information contained within any specific block of data, the recipient must communicate and obtain the public/private key combination necessary to open the block of data. 
Table 1. Connecting blockchain functionality to continuous accounting

\begin{tabular}{ll}
\hline Functionality & Shift toward continuous accounting \\
\hline Immutability & $\begin{array}{l}\text { Easily identifiable audit trail since records can only be changed through addition of } \\
\text { additional blocks }\end{array}$ \\
Consensus & $\begin{array}{l}\text { Real time confirmations since network members approve data as it is added to the } \\
\text { blockchain }\end{array}$ \\
Decentralized & $\begin{array}{l}\text { No single point of failure reducing the need for information requests on a periodic } \\
\text { basis }\end{array}$ \\
Encrypted & $\begin{array}{l}\text { Secure review and analysis of data allowing more continuous review and analysis of } \\
\text { information }\end{array}$
\end{tabular}

Regardless of the specific technical applications of blockchain technology, however, is the fact that, although blockchain technology and platforms may have received increased attention and media coverage, that none of the components embedded in this technology are necessarily innovative or new entrants to the market. Accounting information systems (AIS) have long played a large role in the role the accounting and business process, but appear to be evolving alongside broader business changes to help spur innovation, creativity, and perhaps even new business models (Delmond, Coelho, Keravel, \& Mahl, 2017). The implications of blockchain technology on both the broader business environment and the accounting profession, appear to be connected to the core functionality of the accounting and finance profession.

Accounting and finance professionals, traditionally, have focused on compiling, analyzing, and reporting a relatively narrow view and scope of information, namely the sets of data and information applicable and interesting to shareholders and creditors. A critical flaw in the current financial reporting processes, even with the increased integration of technology throughout the process, is that data and information are not available in a secure and continuous manner. Linking back to accounting and finance at a high level, parsing and reporting information from the organizational generators to external end users, blockchain technology and other technology tools are positioned to drive innovation and creativity throughout the profession (Banham, 2017). Specifically, the implementation and further refinement of blockchain tools will assist professionals employed within industry and public practice generating and communicating the more comprehensive reporting expected by market users.

\subsection{Artificial Intelligence}

Artificial intelligence may have been a part of the practitioner and media conversation for several decades, augmented by appearances and features in motion picture events, but it appears that the accounting implications of $\mathrm{AI}$ are just emerging as an important force in the landscape. Drilling down to the core concepts of idea, and cutting through the potential hype and over excitement that all too often accompanies a new technology tool, the following definition of AI can be constructed. A working definition that appears appropriate for the purposes of this research is that artificial intelligence is either a suite of programs or individual program that can replicate certain facets of human behavior and engagement in some situations. As artificial intelligence increasingly becomes more sophisticated and able to learn through training protocols, the implications and ramifications of this tool continue to increase. Interesting from a technical perspective, the integration of AI tools throughout the accounting and business landscape also hold potential in the following areas of accounting and attest work.

1) Accounting work will become more automated - a large percentage of the work performed by accounting and finance professionals in the current marketplace consists of analyzing, quantifying, and reporting relatively large amounts of quantitative information. One of the most obvious utilizations of AI tools is to automate some of the analyses, freeing up professionals to instead focus on forward level advisory guidance and other services.

2) Lower level tasks will become automated - one of the most tangible effects and impacts of artificial intelligence appears to be the relationship that increased technology investment will have on job automation and delegation. Linking back to point \#1, as tasks are automated it is logical to conclude that the tasks that will initially be automated will be aligned with what many early career professionals spend the majority of working hours doing.

3) Data will be treated as a competitive advantage - with the ubiquity of information and continuous data production increasingly moving from a theoretical idea to a definitive construct, making effective use of this information is imperative. Regardless of which industry or geographic region is highlighted or examined, a 
consistent theme does appear to emerge. Put simply, organizations best able to make use of data, either produced internally or gathered from external sources, are the organizations who seize and maintain leadership positions in the market.

4) Disruption will emerge - disruption is a force, trend, and concept that continues to produce ripple effects and changes in the accounting and finance profession. Virtually any area of the profession, including advisory, attest, tax reporting, and for professionals employed within industry, technology and the increased importance of information as a business tool is changing the profession. Demographic changes, increased technology forces driving business model changes, consolidation pressures, a change of information from centralization to decentralization models, and other professionals seeking to replicate or duplicate accounting services will inevitably lead to some job displacement among the profession.

5) Opportunities will emerge - clearly along with any technology disruption there will inevitably be job disruption, job elimination, and changes that will echo both among current practitioners and accounting students. As AI, blockchain, financial technology, and other technology tools continue to permeate the marketplace, CPAs and other financial professionals will also have more opportunities for growth and expansion. Drilling down, opportunities will be available both in terms of current business offerings, as well as opening doors for differentiated options.

Table 2. Implications of AI on accounting functions

\begin{tabular}{ll}
\hline Implications of AI & Shift toward continuous accounting \\
\hline Automation & $\begin{array}{l}\text { Automation of less value added tasks allows more time to focus on advisory } \\
\text { services and strategy }\end{array}$ \\
Job displacement & $\begin{array}{l}\text { Job losses linked to lower level work will be offset by higher margin options at } \\
\text { higher levels }\end{array}$ \\
Increased availability of information will allow greater insights generated by the \\
business \\
With every technological revolution and implementation there is disruption, \\
Disruption & $\begin{array}{l}\text { aligned with both opportunities and challenges } \\
\text { Continuous accounting and customized reporting allows CPAs and accountants to } \\
\text { add more, and higher margin, services }\end{array}$
\end{tabular}

Put simply, AI appears to be positioned to generate substantive changes in the accounting profession, including, especially as it connects to the importance of information and data to the industry. Data management, communicating this information to both internal and external stakeholders, is an important aspect of the business decision making process. Prior to forward looking guidance, however, it appears appropriate to conduct an examination and analysis of just the differences and implications that increased data intensity will have on the business landscape.

\section{Data as a Competitive Asset}

Data has, rather clearly, played an integral role in the process by which organizations are managed, developed, led, as well as how these results are communicated to both internal and external stakeholder groups. That said, and acknowledging the reality that this concept, the idea of leveraging information to make effective decisions, is not new, the sheer potential and scalability of data processing in the current environment continues to expand. Accounting information systems, different software tools and platforms for data crunching, journal entry posting, and the reporting of results to the marketplace are, and will continue to be, important for both the profession and business at large. Understanding why, framed within the current context and environment, appears to be a logical place to begin an analysis and review of this topic. Drilling down to some of the core connections and linkages bridging the gap between possible disparate areas, there are several areas that appear to be central to understanding the evolution of data into the marketplace.

\subsection{Intellectual Assets and Business}

Intellectual property, intellectual assets, and the increased digitization of information throughout the broader business landscape are increasingly important in the decision making process, and this appears to be reflected in which organizations are positioned as market leaders. Business decision making, regardless of industry lines, appears to be becoming inextricably connected and linked to the intellectual property and information, including the managing and 
development of additional intellectual property alongside broader strategy decisions at the organization (Murthy, 2017). Assets and information linked to the information embedded within the organization can include, but are not limited to intangible assets, customer based information, operational data, industrial information generated via operations, and financial results. These sources of information, of course, are not necessarily creative or innovative in nature, but appear to be increasingly important and essential when framed against current market forces. Specifically, and linking back to the implementation of both artificial intelligence and blockchain technology, digital information and data seem to be assuming an increasingly prominent role. As it pertains to the marketplace, and especially the accounting and finance marketplace, the importance of digital assets, and effectively leveraging digital assets, seem focused in several distinct areas.

The effective leveraging and analysis of both quantitative and qualitative information seems to be a pathway toward marketplace success as well as the implementation of new products and services. It is also worth noting and analyzing that with larger percentages of market capitalization of publicly traded organizations associated with intangible assets this is not merely an academic discussion but a matter with real world implications. Examples of just how intangible assets and intellectual property can be monetized (Menes, 2017) and used for improved can be found across industry lines, and while use cases will differ from organization to organization, several commonalities appear to be represent consistent applications. First, management professionals and teams that can consistently generate intangible assets and other intellectual assets can leverage these to achieve higher valuations than would otherwise occur. Valuations can, clearly, be influenced by a variety of different forces, but with increased focus linked to the potential of intangible assets and property for business, identifying and communicating the specific intangible assets within the organization is an important first step.

Second, intangible assets and intellectual property which can include but are not limited to the information and data contained within the firm, can and should be mined, analyzed, and examined to assist with the decision making process. Over time, the robust development of intellectual property and assets can also develop intersecting areas and functional groups within an organization focused on maximizing the potential of intellectual assets for business purposes (Howard, Withers, \& Tihanyi, 2017). Especially in the age of artificial intelligence, blockchain, and additional data analytics, organizations have the capability and opportunity to unlock insights from information. This may seem like a rather obvious application of technology, but in addition to obtaining greater clarity into current results, making effective use of data can potentially unlock new revenue opportunities. For example, if based on an automated and/or enhanced data examination and analysis, management teams can spot trends or needs ahead of time from current customers this creates an opportunity for new areas of growth.

Third, and arguably one of the most important and customer oriented angles associated with better data is the reduction of errors and mistakes that are possible. This may clearly generate benefits in terms of increased convenience and reduced errors for customers in virtually every industry, but there appear to be two industries in general that increased utilization of information can have tangible, and even life saving effects. Food safety and supply chains, and the variety of information and data contained with health care networks, are both ripe opportunities for data breaches and mismanagement, but also represent an opportunity for increased supervision. The information contained in both of these areas are both valuable for the decision making process and important to institute control over. Data, regardless of source or end use application, is increasingly categorized and treated as a business asset, and this will have a definitive impact on the underlying function of the accounting profession.

\section{Stakeholder Theory}

One of the most commonly referred to shortcomings of current financial reporting and analysis is routinely focused into two areas. First, accounting information and reporting is virtually always focused on a rather narrow set of end users groups, namely creditors and equity shareholders. In the context of a publicly traded organization these stakeholders are relatively simple to identify in the form of shareholders as well as the creditors of the firm. Even if the organization is not publicly traded, however, the usual end users of financial reporting are relatively simply to identify. Owners, partners, providers of financial capital, and other parties most primarily interested in how the organization is performing from a financial results perspective occupy the majority of management thinking. Second, and arguably more important in the context of the increasingly real time marketplace, is the reality that financial information and reporting is done with information that can be, in many cases, 3-6 months out of date. Addressing both of these concerns, the narrow applicability of information currently published and disseminated by organizations, and the time lag that is virtually embedded in the current reporting process, also appears in alignment with the increased importance of stakeholders. 
At first glance it may seem that improved engagement and communication with stakeholders, specifically non-financial stakeholders, is unconnected to the technological forces sweeping the accounting profession. While perhaps a view that is applied in many cases, and represents a simpler view of the market, this represents an incomplete analysis of market dynamics. It is worth noting that many of the advances in technology, automation, and digitization of business information do not only benefit financial shareholders, but virtually all users or organizational data (Drew, 2017). It is also worth understanding and noting at this point that although stakeholder groups may have traditionally not been associated with financial results, this connection does appear to be shifting. Stakeholder groups, regardless of whether they are financial or non-financial in nature, appear to be having an outsized impact on the accounting and business landscape in terms of both how organizations operate, and how results are communicated to different stakeholder groups. Interestingly, a uniquely technological innovation, namely the Internet of Things, appears closely related to improved reporting, increases in operational efficiency, and a platform for more comprehensive reporting that will satisfy both shareholders and stakeholder groups (O'Brien, 2016). In essence, stakeholder reporting and communicating different classes of information to a variety of end users is increasingly a role and responsibility of management teams.

Taking a step back and analyzing the stakeholder market from a broader perspective also uncovers an additional trend aligning financial reporting with stakeholder reporting. Clearly, reporting of operational, employee, supply chain, and environmental information to stakeholder organizations forms a core component of stakeholder reporting. That said, concluding the analysis at this point results in an incomplete view of the shift toward more comprehensive and continuous information. Additionally, and reflecting the increasing important of consumer and operational data to business decision making, regulations such as the GDPR are, in addition to the legal ramifications, also having an effect on business practices. Specifically, the obligation upon organizations to protect and provide customer information is already having an impact on organizations doing business with E.U. citizens, with further ripple effects foreseeable moving forward (Vanberg, 2018). Institutional investors, whether in form of hedge funds, large international asset managers such as Blackrock, or pension funds, control financial investments and assets totaling trillions of dollars. Although traditionally the focus of investment professionals and asset managers has been, unsurprisingly, on the financial returns generated by organizations, there appear to be additional considerations becoming part of the conversation. Specifically, and especially at the worlds largest asset manager, Blackrock, there has been a shift toward a more proactive approach to engaging with stakeholders, advocating for governance issues, and addressing the business from a more comprehensive perspective on how the organization is performing. This evolution represents a definitive shift in which parties and end users are interested in just how the organization is achieving financial results. Taking this into account, and realizing that such institutional investors will still require quantitative information, akin to current financial reporting, represents a potential opportunity for accounting professionals to address this current gap.

Bridging this gap, and connecting the broader changes in the market to the increased automation and digitization and automation of the accounting function is a relatively straight forward and logical task. As non-financial stakeholders and groups, including regulators, NGO groups, consumer groups, and other governmental entities and bodies are increasingly influential, there are two implications that appear closely connected to the accounting profession. First, these stakeholder groups, both of an individual basis and institutional basis, are not only interested in the performance of the organization, but also how these results are achieved in the near and long term. Such as focus on the medium and longer term also necessitates a broader view of the information produced and communicated both internally and externally.

Second, and reflecting the dynamic and fast moving nature of the business landscape, different stakeholder groups are increasingly expecting and requiring these broader varieties of information to be reported on a more continuous basis. Put simply, traditional financial reporting and information, published and issued with a substantial time lag and only applicable to a narrow set of stakeholders, is insufficient when faced with the increasing interest and influence of stakeholder groups. As business decision making on an overall basis continues to increase and become increasingly digital in nature, stakeholder groups are also beginning to exercise financial influence over the reporting of information. 


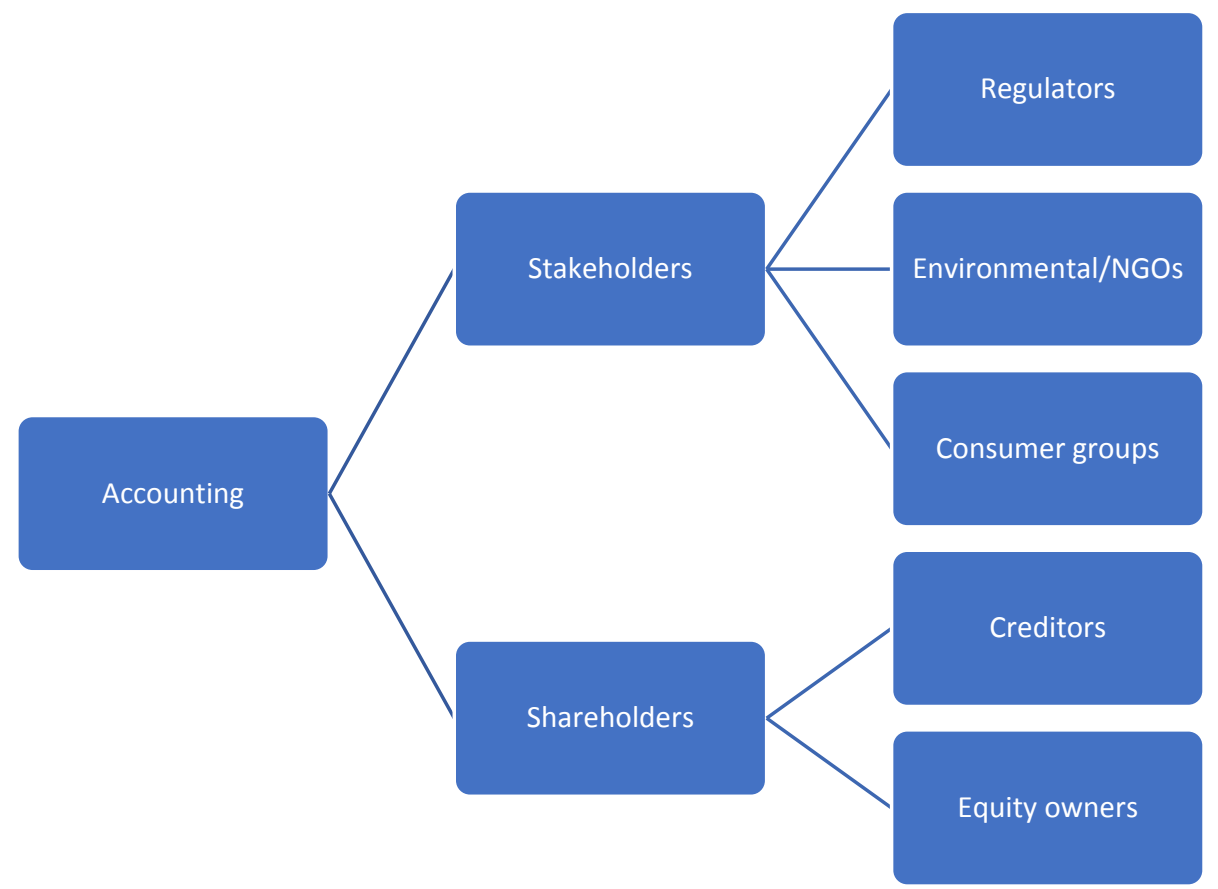

Figure 1. The importance of accounting data in the business landscape

\section{Connecting Stakeholders to Accounting}

It is true that not every stakeholder group or organization has the ability to bring extensive financial resources to a conversation, but the increasing number of financial instruments and investment options focused on ESG (environmental, social, and governance) initiatives appears to point to a fundamental market shift. ESG instruments, rather obviously, illustrate and focus on the importance of not only generating sufficient returns, but doing so in a manner that is conducive to longer term growth. In addition to, and perhaps more interestingly, the amount of focus, investment, and analysis in these areas requires that organizations produce and communicate these types of information more consistently. Publishing and reporting these types of data requires not only an investment in information systems connected to operational sources, but also a transition to a more continuous form of financial accounting and reporting. Accounting and financial professionals posses several competencies and skills that appear to align with the growing need for stakeholder information focusing on operational, financial, and governance linked sources.

First, accounting professionals are already equipped and trained with the skill sets and mindset to quantify, analyze, report, and communicate quantitative data to both internal and external users. Financial information is clearly quantitative in nature, but it is also worth noting that virtually all pieces of operational data, even unstructured information, tend to have quantitative characteristics. Drilling down, and applying similar tactics used in the analysis of financial data, it appears the accounting professionals are uniquely well positioned to handle the increased amount of data already produced by organizations. Second, and actually more applicable for accounting professionals working both in industry and public practice, technology improvements are already implemented throughout many industrial and non-financial processes. Integrating said improvements, both in mindset and actual operations, links directly to concept and implementation of a more continuous accounting function both in public firms or for professionals employed within industry.

\section{Continuous Accounting Implications}

The very concept of a more continuous accounting function is not necessarily a new or completely innovative idea, but with current technological advances in the marketplace this concept appears to be moving increasingly toward reality. Accounting, regardless of whether the accounting professional is employed in private industry or at a public accounting firm, is still based on a periodic review and analysis of financial information. While it is clear that attest, tax, and advisory services will continue to provide opportunities for accounting professionals and form the foundation of what the profession performs, the matter by which these services are provided appear to be changing and evolving. From available market evidence it does appear that the accounting firms that will be most successful 
moving forward are firms that evolve and transform to keep abreast with market forces (Tysian \& Drew, 2018). Stated in a slightly different manner, current practices and processes linked to how accounting professionals deliver value will be augmented or even replaced entirely by technology forces. This shift, already underway in the market place, will appear to have ramifications for virtually every aspect of the accounting profession. Drilling down, the core areas of attest, tax, and advisory services will be impacted in the following manner, although these projected effects listed herein are not meant to be exhaustive.

First, attestation is perhaps where the most investment and discussion around more continuous accounting services has been focused to date, in terms of both market analysis and academic research. Audit practices, and audit practitioners, are increasingly facing a projected future state where information is available a continuous basis. Specifically, in terms of blockchain technology itself, the verification and approval of data as it is uploaded to the blockchain network itself, this process has a, potentially, a powerful impact on the marketplace. The majority of the investment, research, and applications currently underway, in all objectivity, have tended to gravitate toward the larges firms in the marketplace, but this appears similar to previous technology adoptions. Similar technology adoption curves, across business and consumer products and services, will inevitably be mirrored in the adoption and implementation of blockchain technology. Currently, audit practice and services rely on a periodic examination of limited types of information, reinforced by substantive testing and analytic procedures. Circling back to the core functionality of blockchain technology illustrates just how this technology may very well change and augment current audit practices.

Second, and of particular importance for accounting professionals employed within industry, or practitioners seeking to assume the role of strategic advisor often documented in practitioner literature, the increased technological integration within the accounting profession presents opportunities. For example, the implementation and integration of technology platforms and processes are already having an impact on corporate tax avoidance practices and tax liabilities in both the United States and internationally (Hamilton \& Stekelberg, 2017). Specifically, and perhaps most notably in the current market environment, is that the pace of analysis and reporting, whether it be financial or non-financial data, can now keep pace with the pace at which this information is generated within the business landscape. Accounting professionals, especially those employed within industry and advising business management individuals, are often tasked with analyzing the impact operational performance has on financial results. The increased digitization of both business at large, and specifically accounting processes, presents both challenges and opportunities to practitioners that must be accounted and integrated into how the accounting profession interacts with the business landscape.

Third, and perhaps the most importance implication and application of digitization, regardless of the specific technology in question, is that accounting firms, practitioners, as well managerial professionals, will have to contend the potentially disruptive implications of blockchain, artificial intelligence, and other technology platforms throughout the profession. It appears evident that while technology will unlock opportunities for both practitioners and organizations, it will also lead to disruption within the current hierarchy and structure of the marketplace. What appears to be necessary, regardless of industry of geographic affiliation, is that there appears to be an adoption curve and implementation strategy necessary for accounting professionals to thrive in an increasingly digitized and evolving marketplace.

Finally, it appears worthy to note at this point blockchain, artificial intelligence, and other technology trends have generated a large degree of uncertainty within both the profession and business management discussion in general. Putting together an adoption or implementation schedule of plan, consulting with individuals currently employed within the profession, and working together with technology professionals appears to be a logical process to implement within the current construct. Clearly every organization is different, and will be uniquely equipped to contend with the potential ramifications of adopting technology throughout the accounting and business decision making process, but there do appear to be several core trends able to assist management professionals during this transitional period. This list is not meant to be exhaustive nor all inclusive, but rather provide guidance and suggestions for accounting professionals seeking to adapt to a rapidly changing digital environment.

\subsection{Continuous Accounting Implications}

1) Consider whether increased digitization fits the firm - technology, automation, and the iteration embedded within technology adoption may not always be a thorough fit for every organization. Analyzing both processes internal to the organization that could be improved, and the feedback from clients and customers, internal and external to the organization provides management teams with much needed information and 
insights related to technology. It is important to remember, however, that simply automating processes will not improve them; business fundamentals drive performance.

2) Realize current services will change - in a business environment where data appears to be increasingly ubiquitous, and produced at an ever increasing rate, accounting professionals and organizations will have to adapt and change current service offerings. Put simply, current audit practices and processes, for example, will increasingly appear to be obsolete in the face of continuously produced information and data. In addition, as the audience for organizational data increases in scope, competencies already in existence can be leveraged to produce meaningful reports and insights.

3) Stakeholder reporting is increasingly important - whether it takes the form of integrated reporting or some other type of more comprehensive reporting framework, there does appear to be an underlying reality that stakeholder communication is becoming more important. It is important to recognize the reality that, in addition to non-financial stakeholders such as environmental and consumer groups, institutional investors also expect more comprehensive reporting. Drilling down, the expectations of different stakeholders can range from qualitative discussions and analyses to quantitative dashboards connected to organizational performance.

4) Customized reporting will become more mainstream - in the context of the current marketplace for financial reporting, it appears logical to conclude that, for the most part, the majority of end users receive similar data. While acceptable previously, in the face of a more continuous stream of data being produced by the organization, and expectations of real time updates from end users, increasingly customized reporting may be appropriate. Leveraging the advances in technology, regardless of which specific tool utilized by the organization, appears to provide an opportunity for accounting professional to customize and modify reporting in the face of changing market conditions.

5) Practitioners can assume a leadership role - arguably the most dynamic change experienced by the increased technological integration between the broader business landscape and the accounting profession is the development of a more proactive and leadership oriented accounting function. Put simply, in an environment where data and real time information is prized and leverage as a competitive advantage, accounting professionals appear uniquely well positioned to provide insights that are both meaningful and insightful to management teams. This transition, or evolution, connect directly to the core purpose and thesis of this research. Accounting professionals, whether employed in private industry or public practice, are increasingly expected to play a more strategic role in the development and communication of information, and business assets. The shift toward more comprehensive reporting and analysis need not, based on available literature, represent a challenge but rather an opportunity for proactive and forward looking professionals.

\subsection{Implementation of Continuous Accounting}

It is one thing to recognize and acknowledge the need for a more strategic accounting function, but implementing such a dramatic shift in both how accounting professionals operate and engage with stakeholders represents a unique iteration of both accounting professionals and business at large. It appears logical, as of this research, to state that the majority of such research, adoption, and implementation seems to be taking place at both large accounting firms and larger organizations overall, but this need not represent the conclusion of such efforts. Contending with the potentially disruptive shifts within the business environment, including but not limited to the ramifications driven by technological advances including but not limited to blockchain and artificial intelligence can represent a challenge for even the most well prepared management team. Implementing, and transitioning, form a periodic basis of accounting and reporting focused strictly on financial information to a more comprehensive view of accounting reporting will, invariably, require a transition period and implementation steps. Implementing and transitioning to a more comprehensive accounting function will, virtually in every case, result in some displacement and disruption of current roles, but that does not necessarily mean that digitization should result in job losses or employment reduction. Rather, and ideally illustrated via this implementation roadmap, increased digitization and automation will result in increased opportunities for accounting professionals willing to be proactive and seize upon the improvements generated therein.

First, and perhaps most obviously, is that a conversation and engagement process must be undertaken between accounting professionals, the information technology function, and the ultimate end users of organizational information. This may seem like a relatively simplistic place to begin this conversation, but there does appear to be a gap between accounting, technology professionals, and the management end users at this current. Coordinating 
resources, ensuring that objective and logical conversations are indeed taking place between management and various functional groups are important qualitative and strategic steps that should be taken to maximize the effectiveness of organizational assets. Circling back to the forementioned theme of stakeholder reporting and theory, constructing an appropriate narrative framework with which to conduct and communicate various types of information is essential to successfully engage stakeholders and make the most effective business decisions.

Second, and specifically applicable to accounting practitioners and professionals employed within the industry, are the effects that more automated and continuous accounting will have on employment and the workplace. Effects related to automation, automated processes and procedures, and the requirements for more real time information have already resulted in job displacement and disruption. Whether examined through the lens of practitioners recently entering the workplace or from the perspective of senior partners wishing to ensure a successful exit and retirement, the implications are similar. Technology is having a dramatic effect on the profession, and practitioners will need the ability to keep pace in order to succeed moving forward. This need for change, development, and improved training connects directly to the third implication that a shift toward more continuous accounting will have on the workforce.

Third, a powerful impact that the transition toward a more continuous accounting function will have is the need and necessity of a revamped accounting education system. Whether taking place in the K-12 educational setting, college or university classrooms, or continuing education environments, it appears logical to embed some of the ideas that will be necessary going forward into the accounting curriculum. The specific additions and modifications to curriculum will, of course, vary by institution and educational level, but having this conversation appears a logical place to start improving the job readiness of recent graduates entering an increasingly dynamic workplace. Drilling down, in order to have accounting professionals prepared to take advantage of emerging opportunities, accounting students must, at the very least, be made aware of them during the educational process.

\section{Concluding Thoughts}

As the accounting profession adapts to, and evolves alongside, an increasing digitized and technological marketplace, practitioners should be aware of the changing perception of the profession. Traditionally viewed as record keepers, and verification agents of financial information, it does not appear illogical to conclude that, moving forward, accounting professionals will have a more strategic and managerial oriented role. This optimistic and forward looking perspective, echoed throughout practitioner literature and conferences, does not come without risks. Automation, the sheer speed of change within both the profession and business at large, and the potential of other professional groups assuming traditional accounting functions pose systemic risks to the value and viability of the profession in the near to medium term. That said, and ideally analyzed and examined throughout this research, it does appear that with the greater technological integration throughout the profession, there are opportunities for both expansion of current services as well as the creation of entirely new service lines. Breaking down technology topics, analyzing these tools within the context of current accounting practices appears to generate one clear cut fact moving forward. Accounting processes and the profession at large are evolving with the greater integration and utilization of technological forces, and practitioner's posses the tools and competencies with which to keep pace. Financial services, including accounting, will evolve and become more technology dependent in nature, with the only question being how soon these changes will arrive to particular sector. Adaptability, the willingness to learn, and the ability to leverage existing competencies to address new problems position the profession in a uniquely strong position to thrive in a complex marketplace moving forward.

\section{References}

Banham, R. (2017). Digital disruption creates opportunities. Journal Of Accountancy, 224(2), 1-2.

Carlozo, L. (2017). What is blockchain?. Journal Of Accountancy, 224(1), 1-2.

Delmond, M., Coelho, F., Keravel, A., \& Mahl, R. (2017). How information systems enable digital transformation: A Focus on Business Models and Value Co-Production. IUP Journal Of Business Strategy, 14(3), 7-40.

Drew, J. (2017). Real talk about artificial intelligence and blockchain. Journal Of Accountancy, 224(1), 1-6.

Drew, J. (2018). Paving the way to a new digital world. Journal Of Accountancy, 225(6), 32-37.

Hamilton, R., \& Stekelberg, J. (2017). The effect of high-qualiy information technology on corporate tax avoidance and tax risk. Journal Of Information Systems, 31(2), 83-106. https://doi.org/10.2308/isys-51482

Howard, M. D., Wither, M. C., \& Tihanyi, L. (2017). Knowledge dependence and the formation of director interlocks. Academy Of Management Journal, 60(5), 1986-2013. https://doi.org/10.5465/amj.2015.0499 
Lewis, R., McPartland, J. W., \& Ranjan, R. (2017). Blockchain and financial market innovation. Economic Perspectives, 41(7), 1-17.

O'Brien, H. M. (2016). The internet of things. Journal Of Internet Law, 19(12), 1-20.

Tysiac, K., \& Drew, J. (2018). Accounting firms: The next generation. Journal Of Accountancy, 225(6), 3-9.

Murthy, J. J. (2017). Managing innovation and developing intellectual property strategies for firms. SIES Journal Of Management, 13(1), 82-88.

Menes, P. (2017). A startup will stop if it doesn't own its IP. Intellectual Property \& Technology Law Journal, 29(12), 19-21.

Vanberg, A. D. (2018). The right to data portability in the GDPR: What lessons can be learned from the EU experience?. Journal Of Internet Law, 21(7), 1-19. 